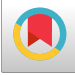

\title{
Epidemiologic Study of Tuberculosis During 2006 - 2015 in Salmas,
}

\section{Iran}

\author{
Javid Taghinejad ${ }^{1}$, Ali Sadeghi Oroumiyeh ${ }^{2,{ }^{*}}$, Babak Barati ${ }^{3}$, Sina Karimi ${ }^{4}$, Mahdi Jahantab ${ }^{4}$ and \\ Shabnam Molayi Kohneshahri ${ }^{5}$ \\ ${ }^{1}$ Department of Microbiology, Malekan Branch, Islamic Azad University, Malekan, Iran \\ ${ }^{2}$ Research Committee, Faculty of Pharmacy, Tabriz University of Medical Sciences, Tabriz, Iran \\ ${ }^{3}$ Biological Sciences and Technology Center, Faculty of Basic Sciences, Imam Hossein University, Tehran, Iran \\ ${ }^{4}$ TB Department, Laboratory of Health Center Staff, Salmas, Iran \\ ${ }^{5}$ Departmant of Microbiology, Zanjan Branch, Faculty of Basic and Medical Sciences, Islamic Azad University, Zanjan, Iran \\ Corresponding author: Research Committee, Faculty of Pharmacy, Tabriz University of Medical Sciences, Tabriz, Iran. E-mail: a_sadeghi70@yahoo.com
}

Received 2018 June 05; Revised 2018 August 06; Accepted 2018 August 07.

\begin{abstract}
Background: Tuberculosis (TB) is an infectious disease which can be lethal in most cases. About 7 million people are infected with TB worldwide. The disease is a major health challenge in developing countries and also in several parts of Iran. Ninety-five percent of 3 million deaths caused by TB annually occur in developing countries. Bearing in mind concerns by WHO about a lack of TB statistics in Iran, this survey aims to study the epidemiology of tuberculosis from 2006 to 2015 in Salmas, Iran.

Methods: This cross-sectional study was carried out on the data obtained from personal health records of 3195 people who were referred to the community health center in Salmas from 2006 to 2015. Patients participated in the study by filling out a checklist. Data was analyzed statistically using version 21 of SPSS software. Chi-square, $t$-test and the Cochran-Armitage $\chi^{2}$ test for trend were performed.

Results: Out of a total of 3195 patients, 84 patients ( 42 male and 42 female) were identified as smear-positive; 42 smear-positive patients were from the urban areas (50\%) and 42 patients from the rural regions (50\%). Of all TB cases, 64 patients were diagnosed with pulmonary tuberculosis (76\%), while 20 patients suffered from extra-pulmonary tuberculosis (24\%). The TB incidence rate was 0.16 .

Conclusions: The present study shows that there is a decline in pulmonary tuberculosis incidence rates in Salmas but extrapulmonary ТВ has shown an increase as a results of poverty, population dynamics, inadequate healthcare, failure to control the diseases, income inequality and physio-psychological stress. Medical care delivered by health providers on a monthly basis is expected to reduce the incidence of tuberculosis in the city in the near future.
\end{abstract}

Keywords: Tuberculosis, Pulmonary, Epidemiology, Statistics

\section{Background}

Tuberculosis (TB) is a chronic contagious infection caused by Mycobacterium tuberculosis in most cases. The most common site of involvement are the lungs, but one third of the cases also involve other organs (1). About 7 million people are infected with TB bacilli worldwide, of which 5 to $10 \%$ may contract the disease. Annually, TB causes 3 million deaths of which 95\% happen in developing countries and 5\% in developed countries (2). In extrapulmonary tuberculosis, almost all body organs are at risk, but the most commonly involved areas are the lymph nodes, pleura, urogenital system, bones, intestines and meninges. Proper pharmacotherapy treats almost all infections caused by susceptible strains. Without treatment, more than half of the cases will die within 5 years. Transmission usually occurs through airborne droplets when an infected person contaminates air by breathing or coughing (3).

Poverty, war, migration, social instability, and homelessness are the factors leading to increase incidences of tuberculosis. Eighty percent of TB cases are concentrated in 22 countries across Asia and Africa. Asian countries such as China, India, Indonesia, Bangladesh, and Pakistan account for more than half of TB cases (4). Two important factors in the spread of $M$. tuberculosis are overcrowding and populations with low inherent resistance. The disease transmits by personal contact with patients. Patients with active tuberculosis placed in a sealed environment can infect peo- 
ple in close contact within 12 hours. A patient with firstline drug-resistant TB could infect people in 4 hours (5). TB prevalence is not the same in all parts of Iran. It has a high prevalence in the border provinces, such as Sistan and Balouchestan, Khorasan, Golestan, Hormozgan and Khuzestan (6). Some studies have reported significant decreases in TB trends in Iran (7-9). This study aims to investigate the epidemiology of tuberculosis in Salmas from 2006 to 2015.

\section{Methods}

This cross-sectional study was designed in Salmas in 2015. Salmas is the capital of Salmas County, West Azerbaijan province, Iran. It is located near the eastern border with Turkey. According to the 2016 census, the city's population is 196546, of which 101440 people live in its urban areas and 95406 people live in the rural areas. Salmas has two community health centers in its urban areas and nine rural health centers. This study was carried out in a central health center laboratory. Personal health records of all patients with suspected pulmonary tuberculosis were inspected. TB cases were defined according to IDSA guidelines (10). The census-sampling method was used and a total of 3195 people were studied. To collect data, a checklist was designed to gather information about age, gender, place of residence, occupation, extra-pulmonary TB background, etc. Data was analyzed statistically with the SPSS software version 21 using descriptive statistics, chi-square and $t$-test at a significance level of $\mathrm{P}<0.05$. Furthermore, the Cochran-Armitage $\chi^{2}$ test for trend was performed. The incidence rate was determined using the following equation:

$$
\text { Incidence rate }=(\text { New cases } / \text { Population at risk }) \times 10^{\mathrm{n}}
$$

\section{Results}

During 2006 - 2015, a group of 3195 patients suspected of tuberculosis were examined. The average age for smearpositive men and women was respectively $42.24 \pm 3.291$ and $43.86 \pm 2.964$, within the age range of under a year to 80 , with a $P$ value of 0.05 . The number of smear-positive patients was identified as 84 , with 42 men (50\%) and 42 women (50\%). In this study, the incidence rate of TB was 0.16 .

Out of 84 infected patients with positive smears, 42 were from the urban areas and 42 (50\%) from the rural regions (50\%). Table 1 shows eight age groups among which the most frequently infected group is aged 51 - 60 while children are the least frequently infected age group.

Tuberculosis was rampant from 2006 to 2008; but the incidence of the disease declined in the following years. In

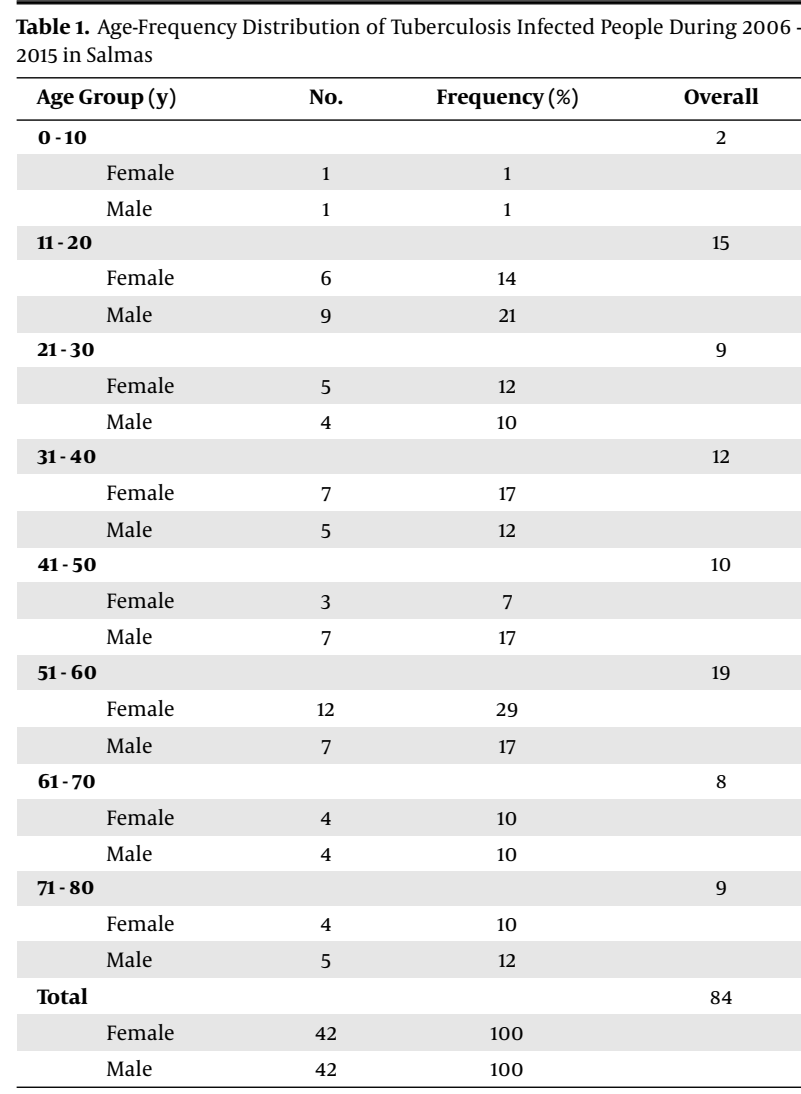

the present study, 64 cases were identified as pulmonary TB (76\%) and 20 cases as extra-pulmonary TB (24\%). Figure 1 shows the frequency of patients based on the type of tuberculosis during the 2006 - 2015 period.

Table 2 indicates the frequency of patients with positive and negative smears (Figure 2). Out of these, 84 people had positive smears (3\%) and 3111 people had negative smears (97\%). In 2008, there were 24 cases who were tested smear-positive, making it the year with the highest preva-

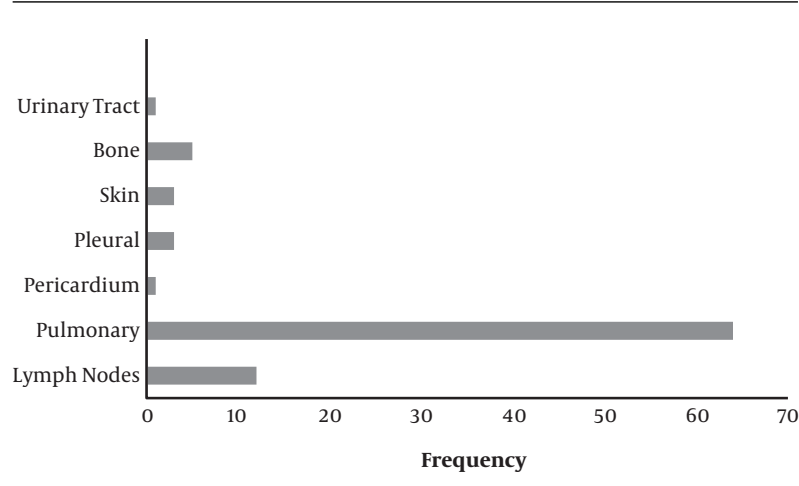

Figure 1. Frequency of patients based on type of tuberculosis during 2006 - 2015 


\begin{tabular}{|c|c|c|c|c|}
\hline Year & & No. & Frequency (\%) & Presumptive $\mathrm{TB}^{\mathrm{a}}$ \\
\hline \multirow[t]{3}{*}{2006} & & & & 343 \\
\hline & Negative smear ${ }^{\mathrm{b}}$ & 320 & 11 & \\
\hline & Positive smear & 23 & 27 & \\
\hline \multirow[t]{3}{*}{2007} & & & & 419 \\
\hline & Negative smear & 399 & 13 & \\
\hline & Positive smear & 20 & 24 & \\
\hline \multirow[t]{3}{*}{2008} & & & & 288 \\
\hline & Negative smear & 264 & 8 & \\
\hline & Positive smear & 24 & 28 & \\
\hline \multirow[t]{3}{*}{2009} & & & & 322 \\
\hline & Negative smear & 319 & 10 & \\
\hline & Positive smear & 3 & 4 & \\
\hline \multirow[t]{3}{*}{2010} & & & & 381 \\
\hline & Negative smear & 377 & 12 & \\
\hline & Positive smear & 4 & 5 & \\
\hline \multirow[t]{3}{*}{2011} & & & & 379 \\
\hline & Negative smear & 376 & 12 & \\
\hline & Positive smear & 3 & 4 & \\
\hline \multirow[t]{3}{*}{2012} & & & & 281 \\
\hline & Negative smear & 277 & 9 & \\
\hline & Positive smear & 4 & 5 & \\
\hline \multirow[t]{3}{*}{2013} & & & & 264 \\
\hline & Negative smear & 263 & 9 & \\
\hline & Positive smear & 1 & 1 & \\
\hline \multirow[t]{3}{*}{2014} & & & & 252 \\
\hline & Negative smear & 251 & 8 & \\
\hline & Positive smear & 1 & 1 & \\
\hline \multirow[t]{3}{*}{2015} & & & & 257 \\
\hline & Negative smear & 256 & 8 & \\
\hline & Positive smear & 1 & 1 & \\
\hline \multirow[t]{3}{*}{ Total } & & & & 3195 \\
\hline & Negative smear & 3111 & 100 & \\
\hline & Positive smear & 84 & 100 & \\
\hline
\end{tabular}

lence of tuberculosis (28\%). The lowest incidence of tuberculosis occurred in 2007 with 399 patients testing negative for their smear. From 2013 to 2015, the incidence of the disease dropped to $1 \%$. In the present study, positive and negative smear averages for patients visiting Salmas Community Health Center over the course of a year were $310.20 \pm$ 17.875 and $8.40 \pm 3.078$, respectively. P value is 0.000 which is less than 0.05 and indicates the insignificance of the correlation. Standard deviation is 56.527 and 9.732 for negative smears and positive smears, respectively. In this study, the trend of TB was not meaningful and a decline was observed.

Table 3 summarizes the annual frequency of urban and rural patients. In 2010, most of the patients were from the urban areas while in 2015 it was the rural patients who had the most visits to the community health center. Moreover,

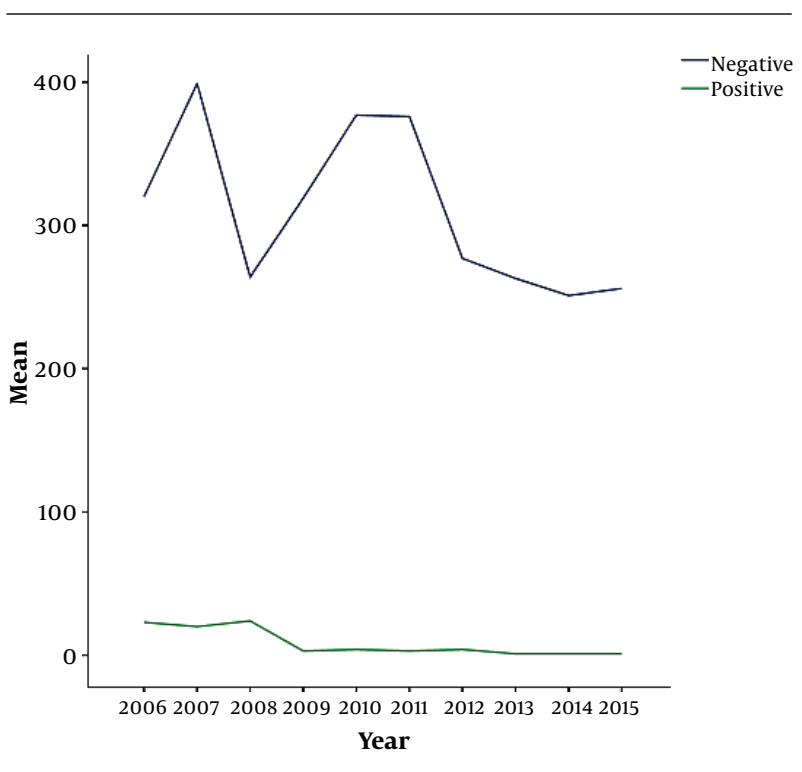

Figure 2. Frequency of patients with positive and negative smear during 2006 - 2015

in 2010, urban patients had the highest frequency of visits but in 2013 it was patients from rural areas who had the most visits to the community health center. In this study, the average for urban and rural visits is $129.00 \pm 20.103$ and $193.200 \pm 12.711$, respectively, which is not significant due to the P value of less than 0.05 .

\section{Discussion}

In 2015, the incidence rate of tuberculosis was estimated to be 10.4 million patients, of whom 5.9 million were men (56\%), 3.5 million were women (34\%), and 1 million were children (10\%), while the newly diagnosed cases of HIV only amounted to 1.2 million (1). Although the overall TB incident rate has declined globally since 2000 , statistics vary in different countries (2). India, Indonesia, China, Nigeria, Pakistan and South Africa accounted for $60 \%$ of the new cases. Major advances in TB prevention and care in these countries determine global progress. From 2014 to 2015 the rate of decline in TB incidence remained at only $1.5 \%$ (1).

Prevalence of TB differs across Iran. Compared with central Iran, border provinces such as Sistan and Balouchestan, Guilan, East and West Azarbaijan, Kudristan, Golestan, Khorasan and the southern coasts show a higher prevalence of TB. Individual circumstances, healthcare, lifestyle, the socio-economic status and environmental variables are factors affecting the prevalence of TB $(3,4)$. Considering that TB is partially controlled in Iran, the high incidence of the disease in border provinces, 


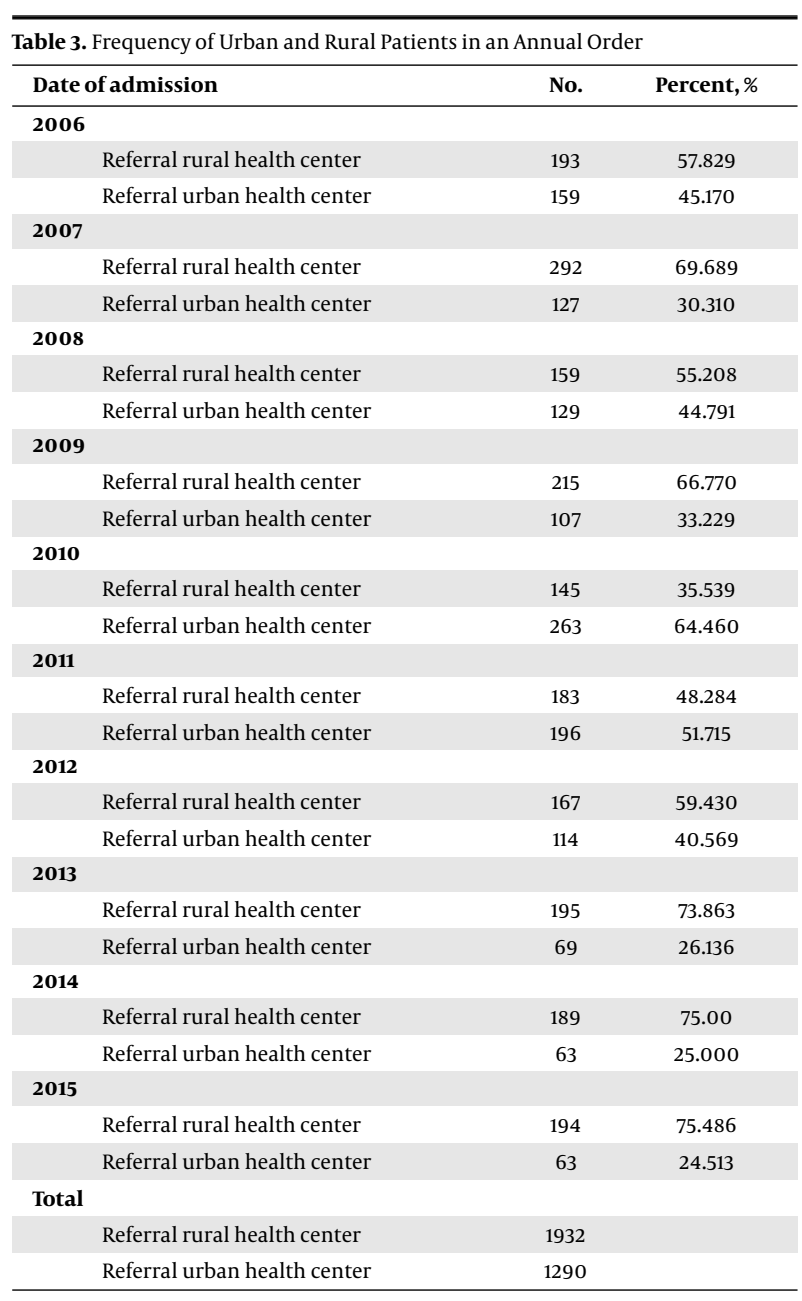

indicates that screening of migrants could play a major role in TB prevention (5).

Since ancient times, humankind has known TB as a chronic pulmonary disease which also involves other body organs. Generally, $85 \%$ of the diagnoses are for pulmonary TB while $15 \%$ of cases manifest as extra-pulmonary TB. The latter involves the lymph nodes, pleura, urogenital system, bones, intestines and meninges (11). Findings of the present study indicate that $68 \%$ of patients were diagnosed with pulmonary TB and 32\% suffered from extrapulmonary $\mathrm{TB}$, involving lymph nodes (15\%), bones (6\%), skin (3\%), pleura (3\%) and other organs (5\%). Metanat et al. reported 23.2\% extra-pulmonary TB manifestations in Zahedan, similar to the findings of Jamshidi et al. in Ilam indicating $19.2 \%$ extra-pulmonary TB manifestations $(6,12)$. Compared to surveys conducted in other parts of Iran, extra-pulmonary TB has shown an increase in this study which could be rooted in poverty, population dynamics, inadequate healthcare, failure to control the diseases, in- come inequality, and physio-psychological stress (13). Due to the lower load of the bacillus, patients suffering from extra-pulmonary TB are tested negative for their smear, making it difficult to diagnose TB (14).

In the survey carried out by Rahmanian et al. in Jahrom, 8.29\% extra-pulmonary TB manifestations were reported which mostly involved the lymph nodes (54.31\%), pleura (22.85\%), and bones (14.28\%) (15). Hazrati et al. reported $43.8 \%$ extra-pulmonary TB manifestations in Ardabil. Lymph nodes (25.4\%), pleura (17.2\%), bone (15.7\%), and eyes (7.5\%) were the most involved organs (16). Ebrahimzadeh et al. reported 70\% pulmonary TB and 30\% extra-pulmonary TB manifestations in Birjand. The latter mostly involved lymph nodes (22.6\%), vertebral column (15.1\%), and pleura (10.3\%) (17). The findings of the present study did not correspond to the surveys conducted in Jahrom and Ardabil but agreed with findings in Birjand.

In the present study, 81 patients were smear-positive (3\%) and 3111 patients were smear-negative (97\%). In the study Gholami et al. carried out in Urmia, 151 patients tested smear-positive (69.1\%) and 97 patients were smearnegative (30.9\%) (18). Mohamadi Azni et al. reported that among 79 patients suffering from pulmonary TB, 38 patients were smear-positive (48\%) and 41 patients were smear-negative (52\%) (19). Beiranvand et al. in Ilam reported that $76.1 \%$ of patients tested positive for their smears and $23.9 \%$ of patients tested negative (20). In the present study, both sexes, shared an equal distribution of TB. Among patients aged 51 to 60 , women with 12 cases of TB outnumbered men. In the study Mohamadi Azni et al. carried out in Damghan, 45 patients were male (50.57\%) and 44 patients were female (49.43\%); 27 cases of TB were reported among patients older than 70 (19). In Urmia, Gholami et al. reported that male patients $(164,66.1 \%)$ outnumbered female patients (84, 33.9\%) (18). Generally, various studies have shown different results worldwide. Some studies pointed to a higher prevalence of TB among women while other surveys stated otherwise (21-24). Different levels of healthcare for men and women in different studies could be the reason for the disagreement. Factors such as education, nutrition, matrimony, diseases (cirrhosis, rheumatic diseases, silicosis, AIDS, chronic kidney and liver diseases), geographic location, exercise, smoking, and alcohol influence TB prevalence and incidence.

\subsection{Conclusion}

It seems that TB is more common among groups tackling overcrowding, malnutrition, poverty, unemployment, political instability, and especially poor health education (25). In order to achieve global targets, there is a drastic need to improve case detection rates, particularly by involving all healthcare providers in DOTS activities (26). Un- 
fortunately, this study failed to reach consensus on information about TB suspect patients. Data collection was restricted because other health centers in Salmas were not able to provide valuable information on their patients. Precise and accurate information on per capita income, health expenditure, health education, illegal immigration, smoking, substance abuse, and access to findings such as clinical symptoms and radiography results would be a tremendous help in evaluating the collected data.

\section{Footnotes}

Authors' Contribution: Study concept and design: Javid Taghinejad; analysis and interpretation of data: Javid Taghinejad and Babak Barati; acquisition of data: Mahdi Jahantab, Sina Karimi and Shabnam Molayi Kohneshahri; drafting of the manuscript: Ali Sadeghi Oroumiyeh and Javid Taghinejad; critical revision of the manuscript for important intellectual content: Ali Sadeghi Oroumiyeh and Babak Barati; statistical analysis: Javid Taghinejad.

Ethical Considerations: There were no ethical considerations.

Financial Disclosure: There are no financial interests related to the material in the manuscript.

Funding/Support: This study was not supported by any funding.

\section{References}

1. World Health Organization. Global actions and investments fall far short of those needed to end the global TB epidemic. Geneva: WHO; 2016.

2. World Health Organization. Global tuberculosis report 2015. WHO; 2015.

3. de Alencar Ximenes RA, de Fatima Pessoa Militao de Albuquerque M, Souza WV, Montarroyos UR, Diniz GT, Luna CF, et al. Is it better to be rich in a poor area or poor in a rich area? A multilevel analysis of a case-control study of social determinants of tuberculosis. Int J Epidemiol. 2009;38(5):1285-96. doi: 10.1093/ije/dyp224. [PubMed: 19656772]. [PubMed Central: PMC2755128].

4. Gupta S, Shenoy VP, Mukhopadhyay C, Bairy I, Muralidharan S. Role of risk factors and socio-economic status in pulmonary tuberculosis: A search for the root cause in patients in a tertiary care hospital, South India. Trop Med Int Health. 2011;16(1):74-8. doi: 10.1111/j.13653156.2010.02676.x. [PubMed: 21091857].

5. Pareek M, Greenaway C, Noori T, Munoz J, Zenner D. The impact of migration on tuberculosis epidemiology and control in high-income countries: A review. BMC Med. 2016;14:48. doi: 10.1186/s12916-016-05955. [PubMed: 27004556]. [PubMed Central: PMC4804514].

6. Metanat M, Salehi M, Sharifimoud B, Jahantigh AR, Rouhani Z. Epidemiology of extra pulmonary tuberculosis in Zahedan.Zahedan JRes Med Sci (Tabib-E-Shargh). 2006;7(4):275-82.

7. Khazaei S, Soheilyzad M, Molaeipoor L, Khazaei Z, Rezaeian S, Khazaei $S$. Trend of smear-positive pulmonary tuberculosis in Iran during 1995-2012: A segmented regression model. Int J Prev Med. 2016;7:86. doi: 10.4103/2008-7802.184317. [PubMed: 27413517]. [PubMed Central: PMC4926552].

8. Arsang SH, Kazemnejad A, Amani F. [Applying segmented regression model to analysis the trend of tuberculosis incidence rate in Iran between 1964-2008]. Iran JEpidemiol. 2011;7(3):6-12. Persian.
9. Ukwaja K, Alobu I, Ifebunandu N, Osakwe C, Igwenyi C. From DOTS to the stop TB strategy: DOTS coverage and trend of tuberculosis notification in Ebonyi, southeastern Nigeria, 1998-2009. Pan Afr Med J. 2011;9:12. [PubMed: 22145056]. [PubMed Central: PMC3215534].

10. Lewinsohn DM, Leonard MK, LoBue PA, Cohn DL, Daley CL, Desmond E, et al. Official American Thoracic Society/Infectious Diseases Society of America/Centers for Disease Control and Prevention Clinical Practice Guidelines: Diagnosis of tuberculosis in adults and children. Clin Infect Dis. 2017;64(2):111-5. doi: 10.1093/cid/ciw778. [PubMed: 28052967]. [PubMed Central: PMC5504475].

11. Heshmati H, Ravanbakhsh K, Khajavi S, Behnampour N. [Epidemiologic study of tuberculosis in Galikesh city during 2006-2011]. Iran J Med Microbiol. 2015;9(1):61-5. Persian.

12. Jamshidi K, Peyman H, Pakzad I, Delpisheh A. [Trends and some risk factors for incidence of tuberculosis in Ilam province (western Iran)]. J Ilam Univ Med Sci. 2011;19(3):32-40. Persian.

13. Stewart GR, Newton SM, Wilkinson KA, Humphreys IR, Murphy HN, Robertson BD, et al. The stress-responsive chaperone alpha-crystallin 2 is required for pathogenesis of Mycobacterium tuberculosis. MolMicrobiol.2005;55(4):1127-37. doi:10.1111/j.1365-2958.2004.04450.x. [PubMed: 15686559].

14. Bennett S, Lienhardt C, Bah-Sow O, Gustafson P, Manneh K, Del Prete $\mathrm{G}$, et al. Investigation of environmental and host-related risk factors for tuberculosis in Africa. II. Investigation of host genetic factors. Am J Epidemiol. 2002;155(11):1074-9. [PubMed: 12034587].

15. Rahmanian V, Rahmanian K, Safary AR, Mansoorian E, Rastgoofard MA. [The epidemiology of tuberculosis in Jahrom (20052014)]. Pars Jahrom Univ Med Sci. 2016;14(4):16-24. Persian. doi: 10.29252/jmj.14.4.16

16. Hazrati S, Khaligh N, Moeini A, Amani F, Barak M, Rahimi G, et al. [Epidemiology of tuberculosis in Ardabil city from 2005 to 2010].J Health Hygiene. 2013;4(2):103 To 109. Persian.

17. Ebrahimzadeh A, Sharifzadeh GR, Eshaghi S. [The epidemiology of tuberculosis in Birjand (1996-2006)].JBirjand Univ Med Sci.2009;16(1):318. Persian.

18. Gholami A, Gharah Aghaji R, Mousavi Jahromi L, Sadaghianifar A. [Epidemiologic survey of pulmonary tuberculosis in Urmia city during 2004-2007]. Knowl Health. 2009;4(3):19-23. Persian.

19. Mohamadi Azni S, Mansourian AA, Nokandeh Z. [Epidemiological study of tuberculosis in Damghan city (Iran) during 2003-2007]. Koomesh. 2008:315-9. Persian.

20. Beiranvand R, Ghalavandi S, Delpisheh A, Sayemiri K, Karimi A. [Epidemiological investigation of tuberculosis in Ilam province between 2005-2011]. Sci Jlam Univ Med Sci. 2014;21(7):1-8. Persian.

21. Nhamoyebonde S, Leslie A. Biological differences between the sexes and susceptibility to tuberculosis. J Infect Dis. 2014;209 Suppl 3:S1006. doi: 10.1093/infdis/jiu147. [PubMed: 24966189].

22. Melzer M, Storring RA, Bagg LR. Tuberculosis in an area bordering east London: Significant local variations when compared to national data. Infection. 2000;28(2):103-5. [PubMed: 10782396].

23. Kodmon C, Zucs P, van der Werf MJ. Migration-related tuberculosis: Epidemiology and characteristics of tuberculosis cases originating outside the European Union and European Economic Area, 2007 to 2013. Euro Surveill. 2016;21(12). doi: 10.2807/15607917.ES.2016.21.12.30164. [PubMed: 27039665].

24. Beaute J, Dara M, de Colombani P, Ehsani S, Gozalov O, Hovanesyan A, et al. Tuberculosis surveillance and monitoring in Europe 2017. European Centre for Disease Prevention and Control; 2017.

25. Metanat M, Sharifi-Mood B, Alavi-Naini R, Aminianfar M. [The epidemiology of tuberculosis in recent years: Reviewing the status in south-eastern Iran]. Zahedan J Res Med Sci. 2012;13(9):1-7. Persian.

26. Palwatwichai A. Tuberculosis in Thailand. Respirology. 2001;6(1):6570. [PubMed: 11264766]. 